\title{
A educação superior em prova: o perfil da educação superior apresentado pelos resultados do Enade 2005 e $2006^{1}$
}

\section{Higher education in proof: the profile of higher education presented by the results of Enade 2005 and 2006}

\author{
José Carlos Rothen ${ }^{[a]}$, Fernanda Nasciutti ${ }^{[b]}$ \\ [a] Doutor em Educação, professor da Universidade Federal de São Carlos (UFSCar), São Carlos, SP, \\ Brasil, e-mail: josecarlos@rothen.pro.br \\ [b] Mestre em Educação Superior, coordenadora do curso de Educação Física da Faculdade Atenas, \\ Paracatu, MG, Brasil, e-mail: nasciutti30@ig.com.br
}

\section{Resumo}

Este artigo tem como objetivo discutir se a educação superior brasileira cumpre o papel de democratizar as oportunidades ou, ao contrário, aumenta as diferenças entre os indivíduos. Para isso, analisam-se os resultados do Enade 2005 e 2006, compara-se o desempenho dos alunos ingressantes com o dos concluintes. Com o estudo observa-se que nas questões de formação profissional o desempenho dos concluintes é superior ao dos

1 Este artigo é uma versão revisada do texto apresentado com o mesmo título na 31a Reunião Anual da ANPED. 
calouros. Contudo, verifica-se que o desnível cultural científico dos egressos é maior do que dos ingressantes, a tal ponto que a maioria dos concluintes não consegue elaborar uma resposta às questões discursivas de sua formação profissional. Conclui-se que os resultados do Enade reforçam a ideia de que a superação da elitização da educação superior brasileira não se resolve apenas ampliando o acesso, mas principalmente na qualificação da permanência do aluno.

Palavra-chave: Educação superior. Enade. Avaliação da educação.

\section{Abstract}

The aim of this paper is to discuss if the Brazilian higher Education does the function of democratizing the opportunities, or if, the difference between people gets higher. For that, the results of Enade 2005 and 2006 are analyzed, comparing the performance of the entering students with the senior student. As result of the study, observes that in questions about professional area, the development of the senior student is higher than the entrant, however the scientific cultural gap is higher for graduates than for freshman, the way that the majority of senior student cannot prepare an answer for discursive questions about professional area. Concludes that the Enade results reinforces the idea that the overcoming of gentrification on Brazilian Superior Education does not resolves it self just taking access bigger, but mainly in qualification of student permanence.

Keywords: Higher education. Enade. Evaluation of education.

\section{Introdução}

A educação superior, historicamente, é vista como um trampolim de ascensão social e como um diferencial a ser utilizado no mercado de trabalho. Essa visão baseia-se principalmente na teoria do capital humano, a qual compreende que a educação superior agrega ao indivíduo um valor, diferenciando-o dos demais, nos termos atuais, torna-o empregável, ou seja, um indivíduo que atende às exigências do mercado de trabalho. 
Ainda na versão liberal, a educação também é compreendida como um instrumento de democratização, pois ela ofereceria a todos as mesmas oportunidades de aprimoramento das potencialidades individuais.

Este artigo discute se a democratização do acesso à Educação permite a superação das desigualdades educacionais ou, ao contrário, aumenta as diferenças entre os indivíduos. Com esse objetivo tomam-se como objeto de análise os resultados do Exame Nacional de Desempenho dos Estudantes (Enade) dos anos de 2005 e 2006.

Em um primeiro momento far-se-á o resgate histórico da realização de exames pelos estudantes da educação superior brasileira. Posteriormente, a exposição da metodologia da coleta de dados e, finalmente, a apresentação da análise dos resultados dos exames.

\section{Os exames nacionais}

Na segunda metade da década de 1990, no governo Fernando Henrique Cardoso, gradualmente implantou-se uma sistemática de avaliação da educação superior, a qual tinha como instrumento prioritário o Exame Nacional de Cursos (ENC) - conhecido como "Provão". Avaliação essa que era realizada pelos formandos dos cursos de graduação da educação superior. O exame teve a sua aplicação pela primeira vez em 1996; o último exame foi realizado no dia 8 de junho de 2003 (INEP, 2007a).

O Provão, instituído pela Lei 9.131/1995, ${ }^{2}$ tinha por objetivo expresso pelo Ministério da Educação traçar um diagnóstico dos cursos avaliados, sustentar os processos de decisão e de formulação de ações voltadas para a melhoria do ensino oferecido nos cursos de graduação, assim constituindo uma das formas de avaliação das instituições de educação superior no que tange aos resultados do processo de ensino-aprendizagem

2 Via decretos foram inseridos no sistema de avaliação o Censo da Educação Superior e a Avaliação em loco das Condições de Ensino; a avaliação da pós-graduação já era realizada pela Capes. 
e um dos mecanismos de interação direta entre o Estado e as Instituições. Ainda no discurso oficial, compreendia-se que ele cumpria papel fundamental ao prestar informações à sociedade sobre a qualidade dos cursos.

Apesar de bastante boicotado, o Provão tornou-se parte da cultura da educação superior no Brasil, o que permitiu que fossem avaliados, anualmente, os cursos de acordo com uma escala que variava em níveis de "A" a "E" Com o exame pretendia-se que os conceitos fornecessem feedback às instituições em relação ao desempenho relativo de seus alunos e auxiliassem os futuros ingressantes na escolha do curso e da instituição. (VERHIME; DANTAS; SOARES, 2006).

Não havia um modelo único de prova, em linhas gerais ela era constituída de testes de conhecimento de formação específica, com questões discursivas e/ou objetivas e um questionário com perguntas que abarcavam os aspectos socioculturais, as expectativas e impressões sobre a própria prova e sobre o curso. Ocorria com periodicidade anual e tinha a sua realização entre os meses de maio e junho. Prestavam o exame todos os alunos que estivessem concluindo o curso durante o ano da aplicação das provas, sendo condição obrigatória, independente do resultado obtido, para obtenção do registro do diploma. Era de responsabilidade da instituição a inscrição do aluno.

Entre as críticas de vários autores destacam-se duas: primeira, a classificação anual dos cursos submetidos ao provão e o ranking dos cursos acentua o espírito de concorrência Institucional diminuindo, assim, a possibilidade de cooperação, sobretudo entre as instituições particulares. A segunda é que no provão não se consideravam os conhecimentos prévios de cada aluno, pois não se poderia negar que alguns alunos já chegavam ao curso com uma bagagem maior de conhecimento e dessa maneira a nota que eles tiravam no provão não significava o que eles realmente tinham aprendido durante o curso. ${ }^{3}$

3 Sobre as criticas ao Provão ver Verhine, Dantas e Soares (2006) e Santos Filho (2000). 


\section{Enade}

Enfim, após tantas análises e críticas, a mudança do Provão foi amplamente debatida e já no primeiro ano do governo Luiz Inácio Lula da Silva instituiu-se a Comissão Especial de Avaliação, com o objetivo de propor mudanças significativas nos procedimentos de avaliação do ensino superior. Em agosto de 2003 foi proposto um novo sistema, denominado Sistema Nacional de Avaliação da Educação Superior (Sinaes). Após discussão no Congresso, foi oficialmente instituído pela Lei Federal 10.861/2004, que incluía uma nova abordagem para o exame de cursos.

O Enade originalmente não teve a centralidade no processo de avaliação, como ocorria na época do Provão. A legislação prevê que sozinho o exame não teria efeitos na regulação estatal (RISTOFF; LIMANA, 2008 , p. 1). Na sua concepção o exame foi compreendido como fazendo parte da avaliação institucional, gerando reflexão sobre a prática institucional ao fornecer "subsídios para que as IES alimentem a dinâmica da autoavaliação quanto na formulação de políticas públicas para o sistema" (POLIDORI; MARINHO-ARAUJO; BARREYRO, 2006, p. 434). Contrariando o espírito da legislação e dos documentos oficiais, a partir de 2008 o Ministério resgatou a centralidade do Enade, sobretudo, com a criação do Conceito Preliminar de Cursos (CPC) e do Índice Geral de Cursos (IGC) como instrumentos para a supervisão e a regulação da educação superior. (ROTHEN; BARREYRO, 2009).

As seguintes características estruturam o novo exame:

- aplicado aos alunos ingressantes (alunos que estão no final do primeiro ano do curso) e concluintes da instituição;

- os cursos são avaliados em um ciclo de 3 anos;

- até 2009 apenas uma amostra dos alunos realizava a prova;

- a prova tem a mesma estrutura para todos os cursos: uma parte de Formação Geral (7 questões objetivas e 3 discursivas) ${ }^{4}$ e

4 A prova de 2004 contava com 8 questões objetivas e 2 discursivas. 
outra de Conhecimentos Específicos. (28 questões objetivas e 2 discursivas).

Simon Schwartzman (2005, p. 1), com o objetivo de "chamar a atenção para alguns problemas e dúvidas mais evidentes, que precisariam ser melhor elucidados", e tendo como ponto de partida os procedimentos utilizados no Enade 2004, aponta que a opção de apenas uma amostra para realizar a prova, no caso $56 \%$ dos alunos, apresenta algumas dificuldades:

a) os alunos selecionados podem não necessariamente ser uma amostragem representativa da turma;

b) é possível não haver lisura no sorteio dos alunos escolhidos. Ele entende que o único ganho nessa opção foi o de diminuir o custo na correção das questões discursivas e que na aplicação de questionários essa redução não teria sido significativa.

Em relação à parte de formação geral, Schwartzman (2005, p. 3) afirma que a prova foi muito pretensiosa: buscou-se analisar 30 dimensões diferentes em 10 questões. Segundo a interpretação do autor, para avaliação de cada uma das dimensões seria necessária uma bateria de itens. Posição essa compartilhada por Verhine, Dantas e Soares (2006, p. 300), indo além, tais autores afirmam que não existe estudo no sentido de saber se o número de questões é adequado e se elas realmente avaliam as dimensões propostas.

Ao tomarem-se os dados do Enade para análise é necessário levar em consideração as seguintes ressalvas ou limitações do instrumento:

- o Enade avalia apenas habilidades e competências cognitivas necessárias à realização de uma prova, não avaliando outras habilidades, como, por exemplo, as necessárias para procedimentos realizados em laboratórios;

- o Enade avalia o desempenho dos estudantes em dois pontos, não havendo uma avaliação continuada do estudante. Aspectos 
emocionais e de motivação podem, por exemplo, influenciar o desempenho e consequentemente o resultado da avaliação;

- apesar da prova ser a mesma para os ingressantes e concluintes pode haver distorção na identificação no valor agregado, pois o perfil dos concluintes pode ser diferente dos ingressantes;

- apenas uma amostra dos estudantes realiza a prova e, apesar de estudos estatísticos validarem trabalhos por amostragem, o resultado é menos confiável do que provas aplicadas a todos os alunos, como ocorria com o Provão;

- o número de questões da prova é pequeno para avaliar todos os conteúdos, competências e habilidades propostas nas Diretrizes Curriculares e nos objetivos do Enade.

Essas ressalvas apontam para os limites da utilização de exames como diagnósticos definitivos sobre a educação superior, como se pretende nos processos de regulação. Contudo, esse tipo de avaliação é um instrumento eficaz para levantar hipóteses sobre o desenvolvimento da educação superior e levantar diagnósticos parciais sobre o que os exames avaliam, a saber, habilidades cognitivas e conhecimentos adquiridos para responder às questões propostas nos exames.

\section{Metodologia}

Na pesquisa tomou-se como base empírica os dados do Relatório Síntese do Enade 2005 e 2006 publicados pelo Instituto Nacional de Estudos e Pesquisas Anísio Teixeira (INEP, 2007b, c). Do ano de 2005 foram utilizados os resultados dos cursos avaliados, a saber, Arquitetura e Urbanismo, Biologia, Ciências Sociais, Computação, Engenharia, Filosofia, Física, Geografia, História, Letras, Matemática, Pedagogia e Química. É importante ressaltar que os cursos de Biologia, Física, Letras e Química continham, nos relatórios-síntese, dados referentes aos cursos de licenciatura e bacharelado e, para efeito deste estudo, destacaram-se apenas os 
dados dos cursos de bacharelado, sendo essa escolha aleatória. No curso de Computação, colheram-se os dados do bacharelado em sistemas de informação e, no curso de Engenharia, retiraram-se os dados referentes ao grupo 1, ou seja, o da Engenharia Civil.

Do ano de 2006 também foram tomados os dados de todos os cursos avaliados, sendo os seguintes: Administração, Arquivologia, Biomedicina, Biblioteconomia, Ciências Contábeis, Ciências Econômicas, Comunicação Social, Design, Direito, Formação de Professores, Psicologia, Música, Secretariado Executivo e Teatro.

Para análise, os dados foram agrupados conforme a estruturação do Relatório-Síntese: 1. Estatística básica da prova: 1.1 - Quadro geral; 1.2 - Formação geral; 1.3 - Componente específico; 2. Questões objetivas: 2.1 - Componente específico; 2.2 - Componente geral; 3. Questões discursivas; 3.1 - Componente específico; 3.2 - Componente geral.

No Relatório-Síntese, para cada um dos itens são apresentados os resultados do desempenho dos estudantes Ingressantes, Concluintes e o Total, informando: a nota mínima, média, mediana, nota máxima e desvio-padrão. Para o estudo foram tomadas as notas dos alunos Ingressantes e Concluintes, descartando o resultado total, pois o objetivo deste estudo está relacionado com a evolução dos resultados.

Os dados apresentaram alguns problemas:

- a nota mínima em todos os componentes é zero, possivelmente ocasionado por boicotes à prova;

- no item "Formação Geral” "Questões Objetivas”, no Enade 2005, a mediana para todos os cursos é 71,4 e a nota máxima 100. Provavelmente essa coincidência de valores seja fruto de erro na editoração da apresentação dos dados.

Para análise agruparam-se em tabelas os resultados de todos os cursos e calculou-se a percentagem da diferença entre o desempenho dos ingressantes em relação aos concluintes. Este arranjo será apresentado, aqui, em tabelas contendo apenas os dados mais significativos. 


\section{Análise e discussão}

\section{Resultado global}

O resultado global do desempenho dos estudantes no Enade 2005 e 2006 aponta que no geral há um melhor desempenho dos alunos concluintes comparado com os iniciantes.

Tabela 1 - Resultado geral Enade 2005-2006

\begin{tabular}{|c|c|c|c|c|c|}
\hline Curso & & Média & Desvio-padrão & Mediana & Nota máxima \\
\hline \multirow{3}{*}{$\begin{array}{l}\text { Arquitetura e } \\
\text { Urbanismo }\end{array}$} & 1 & 37,4 & 15,8 & 38,7 & 78,8 \\
\hline & $\mathrm{C}$ & 50,4 & 17,9 & 52,4 & 87,9 \\
\hline & $\%$ & $35 \%$ & $13 \%$ & $35 \%$ & $12 \%$ \\
\hline \multirow[t]{3}{*}{ Biblioteconomia } & I & 37,6 & 16,1 & 39,3 & 82,7 \\
\hline & $\mathrm{C}$ & 45,3 & 15,4 & 47,4 & 81,5 \\
\hline & $\%$ & $20 \%$ & $-4 \%$ & $21 \%$ & $-1 \%$ \\
\hline \multirow[t]{3}{*}{ Computação } & I & 30,0 & 10,9 & 29,8 & 80,8 \\
\hline & $\mathrm{C}$ & 39,3 & 14,0 & 39,0 & 86,8 \\
\hline & $\%$ & $31 \%$ & $28 \%$ & $31 \%$ & $7 \%$ \\
\hline \multirow{3}{*}{$\begin{array}{l}\text { Formação de } \\
\text { Professores }\end{array}$} & 1 & 41,1 & 12,1 & 40,6 & 84,2 \\
\hline & $\mathrm{C}$ & 44,5 & 12,6 & 44,1 & 89,9 \\
\hline & $\%$ & $8 \%$ & $4 \%$ & $9 \%$ & $7 \%$ \\
\hline \multirow[t]{3}{*}{ Letras } & 1 & 34,0 & 12,4 & 33,4 & 90,3 \\
\hline & $\mathrm{C}$ & 37,6 & 13,9 & 37,0 & 89,1 \\
\hline & $\%$ & $11 \%$ & $12 \%$ & $11 \%$ & $-1 \%$ \\
\hline \multirow[t]{3}{*}{ Química } & 1 & 28,9 & 11,6 & 28,5 & 69,3 \\
\hline & $\mathrm{C}$ & 36,1 & 13,9 & 36,0 & 86,8 \\
\hline & $\%$ & $25 \%$ & $20 \%$ & $26 \%$ & $25 \%$ \\
\hline \multirow[t]{3}{*}{ Turismo } & 1 & 43,1 & 13,9 & 43,9 & 82,1 \\
\hline & $\mathrm{C}$ & 49,2 & 13,5 & 49,7 & 87,5 \\
\hline & $\%$ & $14 \%$ & $-3 \%$ & $13 \%$ & $7 \%$ \\
\hline
\end{tabular}

Fonte: INEP, 2007b, c.

Legenda: I = ingressante; $\mathrm{C}$ = concluinte; $\%$ = acréscimo em porcentagem. 
O melhor desempenho foi o do curso de Arquitetura e Urbanismo, com um acréscimo de $35 \%$ da nota, e o menor no curso de Formação de Professores (8\%), o acréscimo mais frequente é de 19\%. Essa progressão se confirma na análise da mediana, sendo o melhor desempenho em Arquitetura e Urbanismo (35\%) e o menor em Formação de Professores ( $9 \%)$ e o acréscimo mais frequente de $20 \%$. Na nota máxima, excluindo-se os cursos de Letras e Biblioteconomia, também ocorre um aumento no desempenho dos concluintes, contudo em uma percentagem menor; sendo o maior acréscimo no curso de Química (25\%) e o valor mais frequente de $2 \%$.

A análise do desvio-padrão ${ }^{5}$ aponta que no geral há maior homogeneidade dos alunos ingressantes se comparados com os concluintes, tanto que na maioria dos casos houve um acréscimo em relação aos concluintes comparados com os ingressantes. Sendo o maior acréscimo no curso de Computação (28\%), o decréscimo nos cursos de Biblioteconomia $(-4 \%)$ e no curso de Turismo (-3\%) e o acréscimo mais frequente é de $9 \%$.

A partir dos resultados globais propõem-se aqui as seguintes interpretações/hipóteses:

- o ensino médio proporciona uma educação mais homogênea, ao passo que a educação superior é mais heterogênea;

- a educação superior aumenta as habilidades e conhecimentos dos estudantes necessários para a realização das provas.

\section{Formação geral}

O desempenho dos concluintes comparado com os ingressantes mantém a tendência de melhora observada nos resultados gerais, contudo com ênfase menor.

5 Quanto maior o valor do desvio-padrão, mais heterogênea é a amostra e, quando menor, mais homogênea. 
Nas questões objetivas o desempenho médio dos concluintes é superior em $5 \%$ aos ingressantes. O maior acréscimo no desempenho é no curso de Computação (11\%) e o menor no de Teatro (1\%). Nas questões discursivas o acréscimo médio foi de $8 \%$, o curso que teve maior acréscimo foi o de Arquitetura e Urbanismo (36\%) e nos cursos de Letras e Ciências Contábeis não ocorreu evolução (0\%).

Tabela 2 - Formação geral: questões objetivas

\begin{tabular}{|c|c|c|c|c|c|}
\hline Curso & & Média & Desvio-padrão & Mediana & Nota máxima \\
\hline \multirow{3}{*}{$\begin{array}{l}\text { Arquitetura e } \\
\text { Urbanismo }\end{array}$} & 1 & 63,1 & 25,0 & 71,4 & 100,0 \\
\hline & C & 69,0 & 24,0 & 71,4 & 100,0 \\
\hline & $\%$ & $9 \%$ & $-4 \%$ & $0 \%$ & $0 \%$ \\
\hline \multirow[t]{3}{*}{ Biomedicina } & 1 & 45,0 & 16,7 & 50,0 & 100,0 \\
\hline & $\mathrm{C}$ & 47,8 & 16,5 & 50,0 & 100,0 \\
\hline & $\%$ & $6 \%$ & $-1 \%$ & $0 \%$ & $0 \%$ \\
\hline \multirow{3}{*}{$\begin{array}{l}\text { Ciências } \\
\text { Contábeis }\end{array}$} & 1 & 42,5 & 17,1 & 37,5 & 100,0 \\
\hline & $\mathrm{C}$ & 44,2 & 17,6 & 50,0 & 100,0 \\
\hline & $\%$ & $4 \%$ & $3 \%$ & $33 \%$ & $0 \%$ \\
\hline \multirow[t]{3}{*}{ Computação } & 1 & 63,8 & 23,5 & 71,4 & 100,0 \\
\hline & $\mathrm{C}$ & 70,6 & 22,2 & 71,4 & 100,0 \\
\hline & $\%$ & $11 \%$ & $-6 \%$ & $0 \%$ & $0 \%$ \\
\hline \multirow[t]{3}{*}{ Design } & 1 & 46,3 & 17,7 & 50,0 & 100,0 \\
\hline & $\mathrm{C}$ & 49,7 & 17,3 & 50,0 & 100,0 \\
\hline & $\%$ & $7 \%$ & $-2 \%$ & $0 \%$ & $0 \%$ \\
\hline \multirow[t]{3}{*}{ Letras } & 1 & 65,9 & 22,3 & 71,4 & 100,0 \\
\hline & C & 68,4 & 22,1 & 71,4 & 100,0 \\
\hline & $\%$ & $4 \%$ & $-1 \%$ & $0 \%$ & $0 \%$ \\
\hline \multirow[t]{3}{*}{ Turismo } & I & 47,8 & 19,4 & 42,9 & 100,0 \\
\hline & $\mathrm{C}$ & 50,1 & 18,9 & 57,1 & 100,0 \\
\hline & $\%$ & $5 \%$ & $-3 \%$ & $33 \%$ & $0 \%$ \\
\hline
\end{tabular}

Fonte: INEP, 2007b, c.

Legenda: $\mathrm{I}$ = ingressante; $\mathrm{C}=$ concluinte; $\%$ = acréscimo em porcentagem. 
Tabela 3 - Formação geral: questões discursivas

\begin{tabular}{|c|c|c|c|c|c|}
\hline Curso & & Média & Desvio-padrão & Mediana & Nota máxima \\
\hline \multirow{3}{*}{$\begin{array}{l}\text { Arquitetura e } \\
\text { Urbanismo }\end{array}$} & 1 & 41,7 & 18,8 & 42,9 & 95,2 \\
\hline & C & 56,7 & 19,8 & 61,9 & 95,2 \\
\hline & $\%$ & $36 \%$ & $5 \%$ & $44 \%$ & $0 \%$ \\
\hline \multirow[t]{3}{*}{ Biomedicina } & 1 & 48,0 & 23,1 & 50,0 & 100,0 \\
\hline & $\mathrm{C}$ & 49,6 & 21,7 & 50,0 & 100,0 \\
\hline & $\%$ & $3 \%$ & $-6 \%$ & $0 \%$ & $0 \%$ \\
\hline \multirow{3}{*}{$\begin{array}{l}\text { Ciências } \\
\text { Contábeis }\end{array}$} & 1 & 45,4 & 26,0 & 50,0 & 100,0 \\
\hline & $\mathrm{C}$ & 45,5 & 26,6 & 50,0 & 100,0 \\
\hline & $\%$ & $0 \%$ & $2 \%$ & $0 \%$ & $0 \%$ \\
\hline \multirow[t]{3}{*}{ Computação } & 1 & 38,4 & 21,3 & 41,7 & 100,0 \\
\hline & C & 43,3 & 21,1 & 46,7 & 96,7 \\
\hline & $\%$ & $13 \%$ & $-1 \%$ & $12 \%$ & $-3 \%$ \\
\hline \multirow[t]{3}{*}{ Design } & 1 & 47,3 & 24,0 & 52,5 & 100,0 \\
\hline & C & 51,5 & 22,5 & 57,5 & 100,0 \\
\hline & $\%$ & $9 \%$ & $-6 \%$ & $10 \%$ & $0 \%$ \\
\hline \multirow[t]{3}{*}{ Letras } & 1 & 44,3 & 23,1 & 48,3 & 100,0 \\
\hline & $\mathrm{C}$ & 44,4 & 23,5 & 48,3 & 100,0 \\
\hline & $\%$ & $0 \%$ & $2 \%$ & $0 \%$ & $0 \%$ \\
\hline \multirow[t]{3}{*}{ Turismo } & I & 48,8 & 23,2 & 55,0 & 100,0 \\
\hline & $\mathrm{C}$ & 52,7 & 22,1 & 57,5 & 100,0 \\
\hline & $\%$ & $8 \%$ & $-5 \%$ & $5 \%$ & $0 \%$ \\
\hline
\end{tabular}

Fonte: INEP, 2007b, c.

Legenda: $\mathrm{I}$ = ingressante; $\mathrm{C}=$ concluinte; $\%$ = acréscimo em porcentagem.

Ao analisar o desvio-padrão observa-se que na média os cursos mantiveram o seu grau de heterogeneidade. No curso de Teatro, o desviopadrão dos concluintes foi $8 \%$ maior e nos cursos de Design e Biomedicina houve um decréscimo de $8 \%$, assim, no curso de teatro os concluintes têm um desempenho mais heterogêneo do que os ingressantes, nos outros dois cursos o desempenho dos concluintes é mais homogêneo. 
Comparando os dados da formação geral com o resultado global conclui-se que nessa parte da prova o acréscimo não é tão significativo. Como explicação a esse fato levantam-se aqui as seguintes hipóteses:

- muitos dos cursos de ensino médio preparam os seus estudantes para a realização de provas de ingresso na educação superior, esse tipo de treinamento pode influenciar no resultado;

- os alunos ingressantes realizam as provas ao final do primeiro ano, no qual normalmente estão inseridas as disciplinas de formação geral, assim, no momento da realização da prova, boa parte da influência que a educação superior teria nessa formação já ocorreu;

- o número de questões é insuficiente para avaliação dos aspectos propostos;

- mesmo aceitando a hipótese anteriormente citada, o resultado aponta para a ideia de que a educação superior não estaria organizada para oferecer grandes acréscimos na formação geral aos estudantes.

\section{Formação específica}

Na formação específica ocorre o maior acréscimo no desempenho dos concluintes.

Nas questões objetivas percentualmente o maior acréscimo na média é de 34\% (Computação) e o menor de 9\% (Formação de Professores), sendo o acréscimo médio de $20 \%$. Comparando com os dados já apresentados, nas questões discursivas o aumento percentual no desempenho dos concluintes é intenso: no curso de Arquitetura e Urbanismo o acréscimo foi de $115 \%$ e o menor acréscimo foi no curso de Formação de Professores (17\%), o acréscimo médio foi de $60 \% .^{6}$

6 Nessa análise desconsideraram-se os cursos nos quais os ingressantes tiveram uma média menor de 10 pontos, com a intenção de corrigir desvios de interpretação. 
Tabela 4 - Formação específica: questões objetivas

\begin{tabular}{|c|c|c|c|c|c|}
\hline Curso & & Média & Desvio-padrão & Mediana & Nota máxima \\
\hline \multirow{3}{*}{$\begin{array}{l}\text { Arquitetura e } \\
\text { Urbanismo }\end{array}$} & 1 & 30,7 & 21,9 & 31,7 & 90,0 \\
\hline & $\mathrm{C}$ & 35,2 & 22,0 & 36,7 & 95,0 \\
\hline & $\%$ & $15 \%$ & $0 \%$ & $16 \%$ & $6 \%$ \\
\hline \multirow[t]{3}{*}{ Biomedicina } & 1 & 36,3 & 14,0 & 35,0 & 90,0 \\
\hline & $\mathrm{C}$ & 48,1 & 15,5 & 45,0 & 95,0 \\
\hline & $\%$ & $33 \%$ & $11 \%$ & $29 \%$ & $6 \%$ \\
\hline \multirow{3}{*}{$\begin{array}{l}\text { Ciências } \\
\text { Contábeis }\end{array}$} & 1 & 28,4 & 11,0 & 30,0 & 85,0 \\
\hline & C & 37,0 & 13,7 & 35,0 & 95,0 \\
\hline & $\%$ & $30 \%$ & $25 \%$ & $17 \%$ & $12 \%$ \\
\hline \multirow[t]{3}{*}{ Computação } & 1 & 26,5 & 12,7 & 27,3 & 81,8 \\
\hline & C & 35,4 & 15,6 & 36,4 & 90,9 \\
\hline & $\%$ & $34 \%$ & $23 \%$ & $33 \%$ & $11 \%$ \\
\hline \multirow[t]{3}{*}{ Engenharia } & 1 & 41,9 & 18,0 & 40,0 & 100,0 \\
\hline & C & 49,9 & 19,0 & 50,0 & 100,0 \\
\hline & $\%$ & $19 \%$ & $6 \%$ & $25 \%$ & $0 \%$ \\
\hline \multirow[t]{3}{*}{ Física } & 1 & 31,2 & 17,4 & 33,3 & 93,3 \\
\hline & C & 39,4 & 21,8 & 40,0 & 100,0 \\
\hline & $\%$ & $26 \%$ & $25 \%$ & $20 \%$ & $7 \%$ \\
\hline \multirow{3}{*}{$\begin{array}{l}\text { Formação de } \\
\text { Professores }\end{array}$} & 1 & 45,5 & 15,4 & 45,5 & 95,5 \\
\hline & $C$ & 49,8 & 15,8 & 50,0 & 100,0 \\
\hline & $\%$ & $9 \%$ & $3 \%$ & $10 \%$ & $5 \%$ \\
\hline
\end{tabular}

Fonte: INEP, 2007b, c.

Legenda: $\mathrm{I}$ = ingressante; $\mathrm{C}$ = concluinte; $\%$ = acréscimo em porcentagem.

Em relação ao desvio-padrão - excluindo nas questões objetivas nos cursos de Turismo, Design e Arquivologia - também ocorre um acréscimo na maioria dos cursos. Nas questões objetivas o maior acréscimo foi de 25\% (Ciências Contábeis e Física) sendo a média 9\%. Por sua vez nas questões discursivas o maior acréscimo foi de 190\% (Engenharia), o menor de 2\% (Formação de Professores) e a média de 42\%. Em linhas 
gerais, nas questões específicas os concluintes são mais heterogêneos que os ingressantes.

Tabela 5 - Formação específica: questões discursivas

\begin{tabular}{|c|c|c|c|c|c|}
\hline Curso & & Média & Desvio-padrão & Mediana & Nota máxima \\
\hline \multirow{3}{*}{$\begin{array}{l}\text { Arquitetura e } \\
\text { Urbanismo }\end{array}$} & I & 14,9 & 17,8 & 6,7 & 86,7 \\
\hline & C & 32,0 & 25,3 & 30,0 & 100,0 \\
\hline & $\%$ & $115 \%$ & $42 \%$ & $348 \%$ & $15 \%$ \\
\hline \multirow[t]{3}{*}{ Biomedicina } & I & 8,5 & 12,4 & 2,5 & 82,5 \\
\hline & $\mathrm{C}$ & 26,6 & 20,4 & 23,8 & 90,0 \\
\hline & $\%$ & $213 \%$ & $65 \%$ & $852 \%$ & $9 \%$ \\
\hline \multirow{3}{*}{$\begin{array}{l}\text { Ciências } \\
\text { Contábeis }\end{array}$} & I & 0,5 & 2,0 & 0 & 53,8 \\
\hline & C & 2,2 & 4,4 & 0 & 100,0 \\
\hline & $\%$ & $340 \%$ & $120 \%$ & & $86 \%$ \\
\hline \multirow[t]{3}{*}{ Computação } & I & 6,8 & 16,2 & 0 & 100,0 \\
\hline & C & 23,2 & 26,7 & 15 & 100,0 \\
\hline & $\%$ & $241 \%$ & $65 \%$ & & $0 \%$ \\
\hline \multirow[t]{3}{*}{ Engenharia } & I & 1,1 & 4,8 & 0 & 46,7 \\
\hline & $\mathrm{C}$ & 11,1 & 13,9 & 0 & 66,7 \\
\hline & $\%$ & $909 \%$ & $190 \%$ & & $43 \%$ \\
\hline \multirow[t]{3}{*}{ Física } & I & 1,7 & 5,4 & 0 & 56,7 \\
\hline & C & 3,6 & 8,6 & 0 & 83,3 \\
\hline & $\%$ & $112 \%$ & $59 \%$ & & $47 \%$ \\
\hline \multirow{3}{*}{$\begin{array}{l}\text { Formação de } \\
\text { Professores }\end{array}$} & I & 21,7 & 15,5 & 20,0 & 80,0 \\
\hline & C & 25,4 & 16,5 & 24,0 & 92,0 \\
\hline & $\%$ & $17 \%$ & $6 \%$ & $20 \%$ & $15 \%$ \\
\hline
\end{tabular}

Fonte: INEP, 2007b, c.

Legenda: I = ingressante; $\mathrm{C}$ = concluinte; \% = acréscimo em porcentagem.

É importante ressaltar que as notas das questões específicas são menores que as notas das questões de formação geral, tanto nas objetivas como nas discursivas. Alguns fatores podem explicar essas diferenças: 
a) no ensino médio, visando ao vestibular, muitos alunos são preparados para responder questões do tipo da prova;

b) o grau de dificuldade das questões específicas pode ser maior que o das questões de formação geral;

c) a qualidade da educação básica é melhor que a da educação superior.

Nas questões discursivas do componente específico o resultado da mediana é inferior à média, nas outras questões elas são próximas. Observa-se que em 10 cursos os ingressantes têm a mediana com valor zero e 5 cursos têm essa mediana para os concluintes. Poderia-se argumentar que isso seria fruto de um intenso boicote dos alunos à prova, contudo essa hipótese é enfraquecida pelo fato de que nas outras questões as medianas são próximas da média. Os dados indicam que alguns alunos com desempenho muito superior elevam a média.

Por outro lado, o desempenho dos concluintes que ocupam o lugar da mediana é muito superior ao dos ingressantes. No curso de Biomedicina o desempenho é $852 \%$ superior, o acréscimo médio é de $141 \%$.

Considera-se que as questões discursivas exigem do aluno maior domínio dos conteúdos, das habilidades e das competências para poderem articular em sua própria linguagem uma resposta. Somado a isso que nas questões de formação geral o fato não se repete, pode-se afirmar que, por um lado, para a maioria dos estudantes, a frequência na educação superior faz diferença na sua formação profissional, por outro, é grande o desnível entre os alunos concluintes.

\section{Análise da maior nota}

Uma das críticas ao Provão é de que ele não media o valor agregado e que muitos cursos recebiam alunos "A" tendo a Instituição pouca influência no desempenho desses alunos, por outra vez, outras Instituições recebiam alunos " $E$ " e levavam esses alunos a " $C$ ", tendo assim dado uma contribuição significativa. 
Se tomarmos a mediana dos alunos concluintes e compararmos com a maior nota dos alunos ingressantes observa-se que sempre a nota do aluno ingressante será maior. ${ }^{7}$ Sendo a menor diferença no curso de Arquivologia, em questões objetivas do componente específico (50\%) e a maior distância 2679\% no curso Física (questão discursiva componente específico). Em pontos percentuais a menor diferença é do curso de Arquivologia - questões objetivas do componente específico (28,6 pontos) e a maior do curso de Letras - componente específico questão discursiva (91,3 pontos).

Para uma análise mais aprofundada seria interessante tomar os Percentis 75 e 90 dos alunos ingressantes (dados que não são apresentados no Relatório-Síntese) e comparar com a mediana dos alunos concluintes, pois a maior nota representa o resultado de um aluno que por alguma particularidade pode ter um desempenho excepcional. Contudo, há forte indício que comprova a ideia de que um grupo de alunos entra na educação superior, tendo como referência os concluintes medianos, com maior domínio dos conteúdos, das competências e das habilidades avaliadas no Enade.

\section{Considerações finais}

O melhor resultado dos alunos concluintes nos leva a perguntar: ele é suficiente ou a diferenciação entre os alunos concluintes e ingressantes deveria ser muito maior? A resposta a essa questão não é fácil, faltam dados comparativos no âmbito internacional que poderiam oferecer referência para análise. Além do mais a resposta a essa questão será diferente para os diversos cursos, por exemplo, os dados permitem afirmar que as diferenças no curso de Arquitetura e Urbanismo são muito mais

7 Como já visto, há problema de apresentação da nota máxima e mediana do item "formação geral questões objetivas" do Enade/2005, por isso elas não foram consideradas aqui. Também foram desconsiderados os dados no qual a mediana é zero, por não ser possível cálculo de porcentagem. 
significativas que no de Formação de Professores. Nesse exemplo, pergunta-se, por que parece que no primeiro o valor agregado é muito maior que no segundo? Aqui, sugere-se que para a resposta a essa questão é necessária uma análise da clientela de cada um dos cursos a partir da análise dos questionários socioeconômicos e da própria prova. A resposta a essa questão poderá colocar em xeque a validade de alguns cursos ou ainda indicar a necessidade de reformulação de práticas pedagógicas ou até das Diretrizes Curriculares.

A diferença de resultados entre a formação geral e os componentes específicos, bem como a conclusão provisória de que se "agrega" mais valor na formação profissional do que na geral permitem afirmar que a educação superior brasileira está organizada no sentido de oferecer formação profissional, sendo a cultural relegada a um segundo plano. $\mathrm{Ou}$, ainda, que há uma divisão clara de tarefas entre a educação básica e a superior: a primeira seria responsável pela formação cultural e a segunda pela profissional.

O Enade reforça a ideia de que a elitização da educação superior brasileira não se dá exclusivamente pelo fato de pequena parte da população ter acesso a ela, mas, também, pelo fato de que os seus egressos têm um desnível cultural científico maior do que os seus ingressantes. Para que a educação superior realmente contribua para diminuir o fosso cultural científico dos seus alunos é necessário, além de políticas de acesso nesse nível de ensino, criar práticas de qualificação da permanência do aluno.

\section{Referências}

BRASIL. Lei 9.131 de 24 de novembro de 1995. Altera dispositivos da Lei n. 4.024, de 20 de dezembro de 1961, e dá outras providências. Diário Oficial [da] República Federativa do Brasil, Poder Legislativo, Brasília, DF, 25 nov. 1995. Seção 1, p. 1-2. Disponível em: <http://www3.dataprev.gov.br/sislex/paginas/ 42/1995/9131.htm>. Acesso em: 23 jul. 2009. 
BRASIL Lei 10.861, de 14 de abril de 2004. Institui o Sistema Nacional de Avaliação da Educação Superior - SINAES e dá outras providências. Diário Oficial [da] República Federativa do Brasil, Poder Legislativo, Brasília, DF, 15 abr. 2004. p. 3-4. Disponível em: <http://www.planalto.gov.br/ccivil_03/_ ato2004-2006/2004/Lei/L10.861.htm>. Acesso em: 23 jul. 2009.

INSTITUTO NACIONAL DE ESTUDOS E PESQUISA - INEP. O que é o Exame Nacional de Cursos? Disponível em: <http://www.inep.gov.br/superior/provao〉. Acesso em: 23 jul. 2007a.

INSTITUTO NACIONAL DE ESTUDOS E PESQUISA - INEP. Relatório síntese Enade 2005. Disponível em: <http://www.inep.gov.br/superior/enade/2005/ relatorios.htm>. Acesso em: 7 jul. 2007b.

INSTITUTO NACIONAL DE ESTUDOS E PESQUISA - INEP. Relatório síntese Enade 2006. Disponível em: <http://www.inep.gov.br/superior/enade/2006/ relatorios.htm>. Acesso em: 7 jun. 2007c.

POLIDORI, M. M.; MARINHO-ARAUJO, C. M.; BARREYRO, G. B. SINAES: perspectivas e desafios na avaliação da educação superior brasileira. Ensaio: avaliação política pública em educação, Rio de Janeiro, v. 14, n. 53, p. 425-436, 2006.

RISTOFF, D.; LIMANA, A. O Enade como parte da avaliação da educação superior. 2008. Disponível em: 〈http://www.cpa.unopar.br/enade.pdf〉. Acesso em: 5 mar. 2009.

ROTHEN, J. C.; BARREYRO, G. B. Avaliação da educação superior no segundo governo Lula: "provão II" ou a reedição de velhas práticas? REUNIÃO ANUAL DA ANPED, 32., 2009, Caxambu, MG. Anais... Caxambu, MG: ANPED, 2009.

SANTOS FILHO, J. C. Análise teórico-política do exame nacional de cursos. In: DIAS SOBRINHO, J.; RISTOFF, D. I. (Org.). Universidade desconstruída: avaliação institucional e resistência. Florianópolis: Insular, 2000. p. 149-179.

SCHWARTZMAN, S. O enigma do Enade. 2005. Disponível em: <http://www. schwartzman.org.br/simon/enade.pdf>. Acesso em: 5 mar. 2008. 
VERHINE, R. E.; DANTAS, L. M. V.; SOARES, J. F. Do Provão ao Enade: uma análise comparativa dos exames nacionais utilizados no Ensino Superior Brasileiro. Ensaio: Avaliação Política Pública em Educação, Rio de Janeiro, v. 14, n. 52, p. 291-310, 2006.

Recebido: 25/03/2010

Received: 03/25/2010

Aprovado: 09/09/2010

Approved: 09/09/2010 